\title{
Comportamento ingestivo de cordeiros alimentados com dietas contendo feno de amoreira
}

\section{Feeding behavior of lambs fed with diets containing mulberry hay}

\author{
Luís Gabriel Alves Cirne ${ }^{1 *}$; Américo Garcia da Silva Sobrinho²; \\ Valéria Teixeira Santana ${ }^{3}$; Felipi Ulian Silva ${ }^{3}$; Natália Ludmila Lins Lima ${ }^{4}$; \\ Emanuel Almeida de Oliveira ${ }^{2}$; Gleidson Giordano Pinto de Carvalho ${ }^{5}$; \\ Nivea Maria Brancacci Lopes Zeola ${ }^{6}$; Roque Takahashi ${ }^{2}$
}

\begin{abstract}
Resumo
O experimento foi conduzido com objetivo de avaliar o comportamento ingestivo de cordeiros alimentados com dietas contendo $0 ; 12,5$ e $25,0 \%$ de feno de amoreira em substituição ao concentrado. Foram utilizados vinte e quatro cordeiros Ile de France, com $25 \mathrm{~kg}$ de peso corporal e aproximadamente 4 meses de idade, confinados, em delineamento experimental inteiramente casualizado. Os tempos diários de alimentação (242,01 min), ruminação (435,48 min) e ócio (762,50 min), o número de bolos ruminados por dia $(658,36)$ e o tempo gasto por bolo $(40,03 \mathrm{seg})$ não foram afetados $(\mathrm{P}>0,05)$ pelos diferentes níveis de feno de amoreira no concentrado. As ingestões voluntárias de matéria seca $(1,258$ $\mathrm{kg} / \mathrm{dia})$ e fibra em detergente neutro $(0,302 \mathrm{~kg} / \mathrm{dia})$, assim como as eficiências de ingestão e ruminação da matéria seca $(316,24$ e $173,54 \mathrm{~g} / \mathrm{h}$, respectivamente) e da fibra em detergente neutro $(75,89$ e 41,68 $\mathrm{g} / \mathrm{h}$, respectivamente) foram semelhantes em todos os tratamentos. A mastigação merícica expressa em hora/dia $(11,29)$ e o número de mastigação expresso por bolo $(72,65)$ e por dia $(47.638,06)$, assim como o número e o tempo gasto por refeição (22,02 refeições e $11,23 \mathrm{~min} / \mathrm{refeição),} \mathrm{ruminação}(25,95$ ruminações e 17,29 min/ruminação) e ócio (41,81 ócios e 18,30 min/ócio) também não foram afetados $(\mathrm{P}>0,05)$. A inclusão de feno de amoreira não alterou a ruminação expressa em g de MS e FDN/bolo (1,91 e 0,46 , respectivamente) e por $\mathrm{min} / \mathrm{kg}$ de MS e FDN (361,51 e 1.505,78, respectivamente), bem como a mastigação total expressa em $\mathrm{min} / \mathrm{kg}$ de MS e FDN (563,70 e 2.347,19, respectivamente). A utilização do feno de amoreira em substituição parcial ao concentrado, não altera o comportamento ingestivo de cordeiros em confinamento.
\end{abstract}

Palavras-chave: Alimentação, ócio, ruminação

\footnotetext{
Abstract

The experiment was conducted to evaluate the feeding behavior of lambs fed with diets containing 0 , 12.5 and $25.0 \%$ of mulberry hay as a substitute for the concentrate. Twenty four Ile de France lambs, non castrated, with $25 \mathrm{~kg}$ of body weight and four months old, confined, in a completely randomized design, were used. The feeding daily time (242.01 minutes), rumination (435.48 minutes) and leisure (762.50

${ }^{1}$ Prof. e Pesquisador, Universidade Federal de Roraima, UFRR, Boa Vista, RR. E-mail: lgabrielcirne@hotmail.com

${ }^{2}$ Profs. e Pesquisadores, Universidade Estadual Paulista, UNESP, Jaboticabal, São Paulo, SP. E-mail: americo@fcav.unesp.br; moroto.oliveira@hotmail.com; takahashi@fcav.unesp.br

${ }^{3}$ Discentes, UNESP, Jaboticabal, São Paulo, SP. E-mail: santana_vt@yahoo.com.br; slow_dr@yahoo.com.br

${ }^{4}$ Discente, Universidade Federal de Minas Gerais, UFMG, Belo Horizonte, MG. E-mail: natludmila@yahoo.com.br

${ }^{5}$ Prof. e Pesquisador, Universidade Federal da Bahia, UFBA, Salvador, BA. E-mail: gleidsongiordano@yahoo.com.br

${ }^{6}$ Pesquisador, UNESP, Jaboticabal, SP. E-mail: nivea.brancacci@ig.com.br

* Autor para correspondência
} 
minutes), the numbers of cakes ruminated per day (658.36) and the time spent per cake $(40.03 \mathrm{sec})$ were not affected $(\mathrm{P}>0.05)$ by different levels of hay in mulberry concentrate. The dry matter voluntary intake $(1.258 \mathrm{~kg} /$ day $)$ and neutral detergent fiber intake $(0.302 \mathrm{~kg} /$ day $)$, as well as the efficiency of dry matter intake and rumination (316.24 and $173.54 \mathrm{~g} / \mathrm{h}$, respectively) and efficiency of neutral detergent fiber intake and rumination (75.89 and $41.68 \mathrm{~g} / \mathrm{h}$, respectively) were similar in all treatments. The ruminating chew expressed in hour/day (11.29) and the number of chews expressed per cake (72.65) and per day (47.638.06), as well as the number and the feeding time (22.02 meals and $11.23 \mathrm{~min} / \mathrm{meal})$, rumination (25.95 ruminations and $17.29 \mathrm{~min} /$ rumination) and idle (41.81 idle and $18.30 \mathrm{~min} /$ idle time), were also not affected $(\mathrm{P}>0.05)$. The inclusion of mulberry hay did not change the rumination expressed in $\mathrm{g}$ of $\mathrm{DM}$ and NDF/cake (1.91 and 0.46, respectively) and $\mathrm{min} / \mathrm{kg}$ of DM and NDF (361.51 and 1.505.78, respectively), as well as the total chew expressed in min/kg of DM and NDF (563.70 and 2.347.19, respectively). The use of mulberry hay partially replacing the concentrated, does not change the feeding behavior of feedlot lambs.

Key words: Food, leisure, rumination

\section{Introdução}

Um dos obstáculos à criação de ovinos em sistemas intensivos é a alimentação que, muitas vezes, onera o sistema de produção. Entre os alimentos concentrados mais utilizados na alimentação animal, destacam-se o milho e o farelo de soja, pois ambos formam excelente combinação de energia e proteína de alto valor biológico. Contudo, o elevado custo destes alimentos constitui fator limitante à sua utilização.

Neste contexto, esforços têm sido despendidos na busca por alimentos alternativos de baixo custo que possam substituir, parcial ou totalmente, os alimentos concentrados como o milho e o farelo de soja de elevado custo (CUNHA et al., 2008; GILAVERTE et al., 2011; SILVA et al., 2011).

A amoreira (Morus sp.) pertence à família Moraceae (TAKAHASHI, 1988), e sua utilização como forrageira, na alimentação ovina, é devido às suas características agrostológicas como adaptação a diferentes solos e climas, fácil propagação vegetativa, capacidade de rebrota, sistema radicular pivotante, com numerosas raízes secundárias e terciárias, que permitem um bom crescimento vegetativo mesmo em períodos secos do ano (FONSECA; FONSECA, 1986). Apresenta produção de massa verde de 25 a 30 t/ha/ano, teor de proteína bruta de 18 a 28\% (BA; GIANG; NGOAN, 2005), nutrientes digestíveis totais de
70\% (PRASAD; REDDY, 1991), boa aceitabilidade (SANCHEZ, 2002) e digestibilidade da matéria seca de 75 a 85\% (BA; GIANG; NGOAN, 2005), que caracterizam esta planta como importante alternativa alimentar (TAKAHASHI, 1988).

O conhecimento do comportamento ingestivo é uma ferramenta de grande importância na avaliação do aproveitamento das dietas, pois possibilita ajustar o manejo alimentar dos animais para obtenção de melhor desempenho produtivo. De acordo com Hodgson (1990), os ruminantes adaptam-se às diversas condições de alimentação, manejo e ambiente, modificando seus parâmetros de comportamento ingestivo para alcançar e manter determinado nível de consumo, compatível com as exigências nutricionais.

Neste sentido, objetivou-se avaliar o comportamento ingestivo de cordeiros Ile de France, alimentados com dietas contendo diferentes porcentagens de feno de amoreira.

\section{Material e Métodos}

O experimento foi desenvolvido no Setor de Ovinocultura do Departamento de Zootecnia da Faculdade de Ciências Agrárias e Veterinárias, FCAV - Unesp, Campus de Jaboticabal, SP.

Foram utilizados 24 cordeiros da raça Ile de France, não castrados, recém-desmamados, com 25 
$\mathrm{kg}$ de peso corporal e aproximadamente 4 meses de idade. Os animais foram alojados em baias individuais, com aproximadamente $1,0 \mathrm{~m}^{2}$, com piso ripado e suspenso, equipadas com comedouro e bebedouro individuais e instaladas em galpão coberto. No início do experimento, os cordeiros foram identificados, desverminados, vacinados com vacina polivalente contra clostridioses, suplementados com vitaminas A, D e E e distribuídos por sorteio nos tratamentos.

As dietas experimentais (Tabela 1) foram calculadas para atender às exigências preconizadas pelo NRC (2007) para cordeiros desmamados com ganhos de peso estimados em $300 \mathrm{~g} /$ dia. A relação volumoso:concentrado das dietas (D) foi 50:50, sendo os tratamentos constituídos pelas dietas
D1: cana-de-açúcar + concentrado sem feno de amoreira; D2: cana-de-açúcar + concentrado com $12,5 \%$ de feno de amoreira e D3: cana-de-açúcar + concentrado com $25,0 \%$ de feno de amoreira. A cana-de-açúcar utilizada foi da variedade forrageira IAC 86-2480 picada em tamanho de partículas de $1,0 \mathrm{~cm}$ e fornecida in natura. As ramas de amoreira, provenientes da Sirgaria do Setor de Sericicultura da FCAV - Unesp, foram cortadas com 60 dias de rebrota, sendo posteriormente desidratadas ao sol até atingirem o ponto de feno inferior a $20 \%$ de umidade (COSTA; RESENDE, 2006). Após fenado, esse material foi moído utilizando-se peneira com malha de $0,8 \mathrm{~mm}$ com o intuito de facilitar a uniformização dos concentrados e evitar a seletividade pelos animais.

Tabela 1. Composição percentual dos ingredientes e bromatológica das dietas experimentais.

\begin{tabular}{lccc}
\hline \multirow{2}{*}{ Composição } & \multicolumn{3}{c}{ Feno de amoreira (\%) } \\
\cline { 2 - 4 } & 0 & 12,5 & 25,0 \\
\hline Percentual (\%) & 50,00 & 50,00 & 50,00 \\
Cana-de-açúcar & - & 12,50 & 25,00 \\
Feno de amoreira & 28,49 & 24,60 & 21,33 \\
Farelo de soja & 17,80 & 9,00 & 0,00 \\
Milho em grão moído & 1,00 & 1,00 & 1,00 \\
Óleo de soja & 0,80 & 0,80 & 0,80 \\
Ureia & 0,50 & 0,50 & 0,50 \\
Suplemento mineral e vitamínico ${ }^{1}$ & 0,47 & 0,43 & 0,25 \\
Calcário calcítico $_{\text {Fosfato bicálcico }}$ & 0,94 & 1,17 & 1,12 \\
Bromatológica (na MS) & & & \\
Matéria seca & 58,44 & 56,94 & 57,18 \\
Matéria orgânica & 93,63 & 92,56 & 91,92 \\
Matéria mineral & 4,17 & 4,99 & 5,87 \\
Proteína bruta & 18,88 & 18,51 & 18,40 \\
Extrato etéreo & 2,88 & 2,55 & 2,21 \\
Lignina & 2,07 & 2,19 & 2,32 \\
Fibra em detergente neutro & 23,56 & 24,26 & 25,01 \\
Fibra em detergente ácido & 14,66 & 15,84 & 17,06 \\
Carboidratos totais & 73,27 & 72,95 & 72,76 \\
Carboidratos não-fibrosos & 23,56 & 24,26 & 25,01 \\
Nutrientes digestíveis totais (\%) & 79,11 & 76,61 & 73,58 \\
Energia metabolizável (Mcal/kg MS) & 2,99 & 2,95 & 2,55 \\
\hline
\end{tabular}

${ }^{1}$ Níveis de garantia por kg do produto: Cálcio $120 \mathrm{~g}$, cloro $90 \mathrm{~g}$, cobalto $10 \mathrm{mg}$, cobre $50 \mathrm{mg}$, enxofre $34 \mathrm{~g}$, ferro $1064 \mathrm{mg}$, fósforo $50 \mathrm{~g}$, iodo $25 \mathrm{mg}$, magnésio $54 \mathrm{~g}$, manganês $1500 \mathrm{mg}$, selênio $20 \mathrm{mg}$, sódio $62 \mathrm{~g}$ e zinco $1600 \mathrm{mg}$, Flúor (Max) 0,73g, vitamina A 100.000 UI, vitamina D3 40.000 UI e vitamina E 600 UI.

Fonte: Elaboração dos autores. 
A alimentação foi fornecida às $7 \mathrm{e}$ às $17 \mathrm{~h}$, de forma a permitir, no mínimo, $10 \%$ de sobras, e diariamente, foi registrado o peso do alimento oferecido e o das sobras, para estimativa de consumo. Amostras dos alimentos fornecidos e das sobras foram coletadas e pré-secas em estufa com circulação de ar forçada a $55{ }^{\circ} \mathrm{C}$, por 72 horas e, posteriormente, moídas em moinho tipo Willey com peneira de crivos de $1 \mathrm{~mm}$ para determinação dos teores de MS, matéria orgânica (MO), matéria mineral (MM), extrato etéreo (EE) e energia bruta (EB), conforme metodologias descritas por Silva e Queiroz (2002). O teor de nitrogênio total das amostras foi obtido pelo método de combustão de Dumas, utilizando-se analisador LECO FP-528 LC, seguindo o procedimento descrito por Etheridge, Pesti e Foster (1998) e multiplicado por 6,25 para se obter o valor de proteína bruta (PB) total. Os teores de lignina, fibra em detergente neutro corrigida para cinzas e proteína (FDNcp) e fibra em detergente ácido (FDA), foram determinados de acordo com Van Soest (1994) e recomendados pelo fabricante do aparelho ANKOM Technology ${ }^{\circledR}$, utilizando-se sacos de ANKOM. Os carboidratos totais (CHOT) foram calculados pela equação: $\mathrm{CT}=100-(\% \mathrm{~PB}$ $+\% \mathrm{EE}+\% \mathrm{MM})$ e os não-fibrosos (CNF), pela diferença entre CHOT e FDNcp, propostas por Sniffen, Connor e Van Soest (1992). O teor de nutrientes digestíveis totais (NDT) observado foi obtido a partir da equação somativa: NDT $=$ PBD $+2,25 \times \mathrm{EED}+\mathrm{FDNcpD}+\mathrm{CNFD}$, em que PBD, EED, FDNcp e CNFD significam, respectivamente, proteína bruta digestível, extrato etéreo digestível, fibra em detergente neutro (isenta de cinzas e proteína) digestível e carboidratos não-fibrosos digestíveis. A energia metabolizável foi obtida a partir do ensaio de digestibilidade e da estimativa da produção de gases no rúmen (BLAXTER, 1962).

O experimento teve duração total de 80 dias: os primeiros 14 dias foram destinados à adaptação dos animais às dietas e ao ambiente e os demais à avaliação de desempenho. O comportamento alimentar dos animais foi determinado nos dois últimos dias do período experimental pela quantificação dos intervalos de tempo durante 24 horas/dia (FISCHER, 1996).

No registro do tempo despendido em alimentação, ruminação e ócio, adotou-se a observação visual dos animais a cada 5 minutos, feita por observadores treinados, em sistema de revezamento e posicionados estrategicamente de modo a não incomodar os animais. As observações foram iniciadas às $6 \mathrm{~h} 00$ da manhã com término no mesmo horário do dia seguinte. No mesmo dia, foi realizada a contagem do número de mastigações merícicas $\mathrm{MM}_{\mathrm{nb}}\left(\mathrm{n}^{\circ}\right.$ /bolo) e do tempo despendido para ruminação de cada bolo $\mathrm{MM}_{\mathrm{tb}}$ (seg/bolo) utilizando-se um cronômetro digital. Para a obtenção das médias das mastigações e do tempo, foram feitas as observações de três bolos ruminais em três períodos diferentes do dia (10:00 às 12:00 horas; 14:00 às 16:00 horas; e 18:00 às 20:00 horas). Foram computados o tempo e o número de mastigações para cada bolo ruminal por animal. Para obtenção do número de bolos diários, procedeu-se à divisão do tempo total de ruminação pelo tempo médio gasto na ruminação de cada bolo, descrito anteriormente. A eficiência de alimentação e ruminação, expressa em gMS/hora e gFDN/ hora, foi obtida pela divisão do consumo médio diário de MS e FDN pelo tempo total despendido em alimentação e/ou ruminação em 24 horas, respectivamente. Essas e outras variáveis obtidas neste experimento, como o tempo de mastigação total (TMT), o número de bolos ruminais por dia (NBR) e o número de mastigações merícicas por dia (MMnd), foram obtidas conforme metodologia descrita por Polli et al. (1996) e Bürger et al. (2000). Durante a coleta de dados, na observação noturna dos animais, o ambiente foi mantido com iluminação artificial.

O delineamento experimental utilizado foi o inteiramente casualizado com 3 tratamentos e 8 repetições, totalizando 24 unidades experimentais. Os resultados foram avaliados por meio de análises de variância e regressão, em que os graus de liberdade foram desdobrados em efeito linear 
ou quadrático, de acordo com os níveis de feno de amoreira. A significância das regressões foi obtida pelo teste $\mathrm{F}$ a $1 \%$ ou $5 \%$ de probabilidade, utilizando-se o Sistema de Análises Estatísticas SISVAR (FERREIRA, 2000).

\section{Resultados e Discussão}

Os tempos diários despendidos nas atividades de alimentação, ruminação e ócio não foram afetados $(\mathrm{P}>0,05)$ pela adição de feno de amoreira em substituição parcial ao concentrado na dieta dos cordeiros; os valores médios registrados foram, respectivamente, de 242,01; 435,48 e 762,50 minutos (Tabela 2). $\mathrm{O}$ fato de as dietas terem sido isonitrogenadas e não apresentarem variações nos teores de fibra (Tabela 1) pode explicar a semelhança entre os tempos das atividades. Alterações nos tempos despendidos nas atividades de alimentação, ruminação e ócio têm sido, frequentemente, observadas em trabalhos nos quais as dietas experimentais apresentaram variações nos teores de fibra (MACEDO et al., 2007; MENDES et al., 2010). Estes resultados corroboram com os obtidos por Carvalho et al. (2008), que, ao avaliarem o comportamento ingestivo de ovinos alimentados com dietas contendo $50 \%$ de concentrado e diferentes porcentagens de farelo de cacau $(0,10,20$ e 30\%) em substituição parcial ao concentrado à base de milho moído e farelo de soja, não verificaram diferenças nas atividades de alimentação, ruminação e ócio.

Tabela 2. Consumos (kg/dia) de matéria seca (CMS) e de fibra em detergente neutro (CFDN), tempo (min) despendido em alimentação, ruminação e ócio, número de bolos ruminados por dia e o tempo gasto por bolo (segundos) em cordeiros alimentados com dietas contendo diferentes níveis de feno de amoreira

\begin{tabular}{|c|c|c|c|c|c|c|}
\hline \multirow{2}{*}{ Item } & \multicolumn{3}{|c|}{ Feno de amoreira (\%) } & \multicolumn{2}{|c|}{ Valor $\mathrm{P}^{1}$} & \multirow{2}{*}{$\mathrm{CV}(\%)^{2}$} \\
\hline & 0 & 12,5 & 25,0 & $\mathrm{~L}$ & $\mathrm{Q}$ & \\
\hline CMS em 24 horas $(\mathrm{kg})$ & 1,181 & 1,349 & 1,244 & 0,802 & 0,534 & 27,37 \\
\hline CFDN em 24 horas (kg) & 0,279 & 0,322 & 0,304 & 0,673 & 0,557 & 27,55 \\
\hline Alimentação (min) & 216,87 & 251,66 & 257,50 & 0,251 & 0,625 & 19,34 \\
\hline Ruminação (min) & 440,62 & 435,83 & 430,00 & 0,838 & 0,991 & 16,36 \\
\hline Ócio (min) & 782,50 & 752,50 & 752,50 & 0,621 & 0,774 & 10,86 \\
\hline Bolos ruminados (no/dia) & 677,33 & 638,16 & 659,60 & 0,829 & 0,671 & 17,11 \\
\hline Tempo mastigações/bolo (seg) & 39,24 & 41,16 & 39,68 & 0,921 & 0,656 & 15,10 \\
\hline
\end{tabular}

${ }^{1} \mathrm{P}=$ probabilidade $;{ }^{2} \mathrm{CV}=$ coeficiente de variação.

Fonte: Elaboração dos autores.

O número de bolos ruminados ( $\mathrm{n}$ \% dia) e o tempo de mastigações/bolo (seg) também não foram afetados $(\mathrm{P}>0,05)$ pela adição de feno de amoreira (Tabela 2), com valores médios de 658,36 e 40,03, respectivamente. $\mathrm{O}$ número de bolos ruminados por dia é dependente do tempo de ruminação e do tempo gasto para ruminar cada bolo, e o fato de não ter ocorrido variação nesses tempos explica a semelhança do número de bolos ruminados (NBR) entre os animais dos tratamentos. Comportamento semelhante foi observado por Carvalho et al. (2006), que, ao estudarem a inclusão de farelo de cacau ou torta de dendê em substituição ao concentrado, nas dietas de ovinos da raça Santa Inês em confinamento, não observaram alterações no número de bolos ruminados (n\%dia) e no tempo de mastigações/bolo (seg); e por Carvalho et al. (2004), ao analisarem a inclusão de farelo de cacau ou torta de dendê no concentrado, na dieta de cabras leiteiras.

Não houve diferença para as eficiências de alimentação e ruminação (g MS e FDN/hora), 
com valores médios registrados para eficiência de alimentação de 316,24 e 75,89 g e para eficiência de ruminação, de 173,54 e 41,68 g, respectivamente, para as frações MS e FDN. Neste estudo, os consumos de MS e FDN (kg/dia) foram semelhantes entre as dietas e apresentaram valores médios, respectivamente, de 1,258 e $0,302 \mathrm{~kg}$ (Tabela 2), o que justifica os resultados obtidos para as eficiências que são diretamente relacionadas ao consumo expresso em $\mathrm{kg} / \mathrm{dia}$. Comportamento semelhante foi observado por Alves et al. (2010) que, ao avaliarem as eficiências de alimentação e ruminação (g MS e FDN/hora) em cordeiros Santa Inês em confinamento, alimentados com dietas com
$60 \%$ de concentrado, não verificaram diferença significativa.

O tempo de mastigação total (hora/dia) não foi alterado (Tabela 3), e isso pode ter ocorrido em função da semelhança entre os tempos despendidos nas atividades de alimentação e ruminação entre os animais dos tratamentos, uma vez que o tempo de mastigação total é obtido pela soma do tempo gasto em alimentação e ruminação em 24 horas. Allen (1997), em revisão da literatura, relatou resultados de 132 tratamentos, médias de 32 experimentos para o tempo de mastigação total, mencionando valor médio de 11,13 hora/dia, similar à média de 11,29 hora/dia observada nesta pesquisa.

Tabela 3. Eficiência de alimentação (MS e FDN, g/h), eficiência de ruminação (MS e FDN, g/h) e mastigação merícicas (hora/dia), ( $\mathrm{n}^{\circ} /$ bolo) e ( $\mathrm{n}^{\%}$ /dia) em cordeiros alimentados com dietas contendo diferentes níveis de feno de amoreira

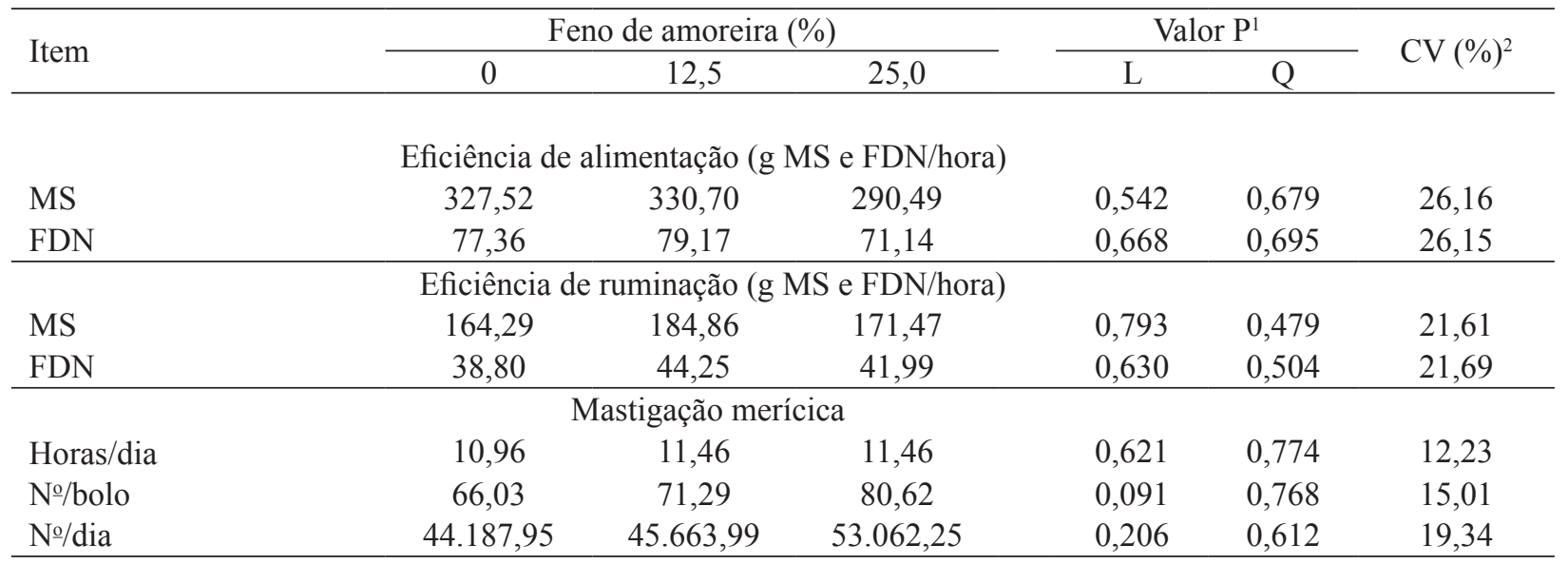

$\mathrm{MS}=$ matéria seca; FDN= fibra em detergente neutro.

${ }^{1} \mathrm{P}=$ probabilidade ${ }^{2} \mathrm{CV}=$ coeficiente de variação.

Fonte: Elaboração dos autores.

Os valores concernentes às mastigações merícicas, expressas em $\mathrm{n}^{0}$ /bolo e $\mathrm{n} \%$ dia, também não sofreram alterações $(\mathrm{P}>0,05)$, com valores médios de 72,65 e 47.638,06, respectivamente. Estes resultados estão de acordo com os encontrados por Pires et al. (2009), que relataram valores médios de 74,80 e 47.336,30 para mastigações merícicas, expressas em $\mathrm{n}^{0}$ /bolo e $\mathrm{n}^{0} /$ dia, respectivamente, em ovinos da raça Santa Inês alimentados com dietas contendo casca de café, farelo de cacau ou farelo de mandioca em substituição parcial ao concentrado.

Não foi observada diferença significativa para número de períodos e o tempo gasto por períodos de refeição (22,02 refeições e 11,23 min/refeição, respectivamente), ruminação (25,95 ruminações e $17,29 \mathrm{~min} /$ ruminação, respectivamente) e ócio 
(41,81 ócios e 18,30 min/ócio, respectivamente), indicando que a inclusão de feno de amoreira não afeta a discretização das séries temporais em ovinos nas condições de alimentação deste experimento (Tabela 4). Como os tempos médios por período de refeição, ruminação e ócio são obtidos pela divisão do tempo total em 24 horas de cada atividade pelo número de períodos diários, estes parâmetros não sofreram alterações em função dos tratamentos. Esta pressuposição foi constatada no trabalho de Alves et al. (2010), que avaliaram o comportamento ingestivo de cordeiros em confinamento.

Tabela 4. Número de períodos ( $\mathrm{n}^{\%} /$ dia) e tempo gasto por período de refeição, ruminação e ócio, consumos de MS e de FDN por refeição $(\mathrm{kg})$ e consumos de MS e de FDN ( $\mathrm{min} / \mathrm{kg}$ ) em cordeiros alimentados com dietas contendo diferentes níveis de feno de amoreira

\begin{tabular}{|c|c|c|c|c|c|c|}
\hline \multirow{2}{*}{ Item } & \multicolumn{3}{|c|}{ Feno de amoreira $(\%)$} & \multicolumn{2}{|c|}{ Valor $\mathrm{P}^{1}$} & \multirow{2}{*}{$\mathrm{CV}(\%)^{2}$} \\
\hline & 0 & 12,5 & 25,0 & $\mathrm{~L}$ & $\mathrm{Q}$ & \\
\hline \multicolumn{7}{|c|}{ Número de período (nºdia) } \\
\hline Refeição & 21,73 & 20,83 & 23,50 & 0,592 & 0,528 & 20,24 \\
\hline Ruminação & 27,87 & 23,50 & 26,50 & 0,573 & 0,104 & 12,82 \\
\hline Ócio & 41,75 & 41,33 & 42,37 & 0,834 & 0,778 & 9,81 \\
\hline \multicolumn{7}{|c|}{ Tempo gasto por períodos (min) } \\
\hline Refeição & 10,55 & 12,27 & 10,87 & 0,855 & 0,318 & 21,41 \\
\hline Ruminação & 15,81 & 19,32 & 16,74 & 0,776 & 0,294 & 25,83 \\
\hline Ócio & 18,76 & 18,23 & 17,91 & 0,548 & 0,931 & 10,45 \\
\hline \multicolumn{7}{|c|}{ Consumo de MS e de FDN por refeição (g) } \\
\hline MS & 58,55 & 65,59 & 51,97 & 0,629 & 0,412 & 31,87 \\
\hline FDN & 13,83 & 15,58 & 12,72 & 0,734 & 0,419 & 31,62 \\
\hline \multicolumn{7}{|c|}{ Consumo de MS e de FDN (min/kg) } \\
\hline MS & 187,95 & 203,55 & 215,06 & 0,557 & 0,959 & 31,12 \\
\hline FDN & 795,76 & 850,26 & 878,18 & 0,667 & 0,936 & 31,11 \\
\hline
\end{tabular}

$\mathrm{MS}=$ matéria seca; FDN= fibra em detergente neutro.

${ }^{1} \mathrm{P}=$ probabilidade; ${ }^{2} \mathrm{CV}=$ coeficiente de variação.

Fonte: Elaboração dos autores.

O consumo de MS e de FDN, expresso em g/ refeição (58,53 e 14,04 g/refeição, respectivamente) e em $\mathrm{min} / \mathrm{kg} \quad(202,19$ e $841,40 \mathrm{~min} / \mathrm{kg}$, respectivamente), também não foi significativo (Tabela 4). Diferenças significativas nessas variáveis seriam esperadas caso o tempo de alimentação, o número de refeições diárias e o consumo de MS e FDN fossem influenciados pela adição de feno de amoreira na dieta dos animais.

A atividade de ruminação, expressa em $g$ de MS e FDN/bolo (1,91 e 0,46 g/bolo, respectivamente), não foi influenciada $(\mathrm{P}>0,05)$ (Tabela 5). Este comportamento pode ser atribuído a semelhança nas ingestões de MS e FDN e no NBR/dia (Tabela 2), uma vez que o valor concernente a g de MS e FDN/bolo é obtido pela divisão do consumo médio diário de MS e FDN pelo NBR/dia. Esta hipótese foi verificada no estudo de Magalhães et al. (2012), que estudaram o comportamento ingestivo de cordeiros, em confinamento, alimentados com dietas à base de cana-de-açúcar.

O tempo de ruminação, expresso em $\mathrm{min} /$ $\mathrm{kg}$ de MS e FDN (361,51 e 1505,78 $\mathrm{min} / \mathrm{kg}$, respectivamente) e o tempo de mastigação total, expresso em min/kg de MS e FDN (563,70 e 2347,19 $\mathrm{min} / \mathrm{kg}$, respectivamente), também, não foram 
afetados $(\mathrm{P}>0,05)$. Estes resultados corroboram aqueles obtidos por Carvalho et al. (2008), que, ao avaliarem níveis de inclusão de farelo de cacau no concentrado, na dieta de ovinos, não constataram diferença no tempo de ruminação e mastigação total, expresso em $\mathrm{min} / \mathrm{kg}$ de MS e FDN.

Tabela 5. Ruminação (g de MS e FDN/bolo), ruminação (min/kg de MS e FDN) e mastigação total (min/kg de MS e FDN) em cordeiros alimentados com dietas contendo diferentes níveis de feno de amoreira

\begin{tabular}{|c|c|c|c|c|c|c|}
\hline \multirow{2}{*}{ Item } & \multicolumn{3}{|c|}{ Feno de amoreira (\%) } & \multicolumn{2}{|c|}{ Valor $\mathrm{P}^{1}$} & \multirow{2}{*}{$\mathrm{CV}(\%)^{2}$} \\
\hline & 0 & 12,5 & 25,0 & $\mathrm{~L}$ & $\mathrm{Q}$ & \\
\hline \multicolumn{7}{|c|}{ Ruminação (g de MS e FDN/bolo) } \\
\hline MS & 1,77 & 2,10 & 1,87 & 0,748 & 0,308 & 22,31 \\
\hline FDN & 0,42 & 0,50 & 0,45 & 0,617 & 0,336 & 22,28 \\
\hline \multicolumn{7}{|c|}{ Ruminação (min/kg de MS e FDN) } \\
\hline MS & 388,16 & 325,31 & 371,05 & 0,797 & 0,357 & 25,27 \\
\hline FDN & $1.643,38$ & $1.358,87$ & $1.515,11$ & 0,645 & 0,370 & 25,30 \\
\hline \multicolumn{7}{|c|}{ Mastigação total (min/kg de MS e FDN) } \\
\hline MS & 576,12 & 528,87 & 586,12 & 0,918 & 0,540 & 23,75 \\
\hline FDN & $2.439,15$ & $2.209,14$ & $2.393,29$ & 0,910 & 0,559 & 23,77 \\
\hline
\end{tabular}

$\mathrm{MS}=$ matéria seca; $\mathrm{FDN}=$ fibra em detergente neutro.

${ }^{1} \mathrm{P}=$ probabilidade ${ }^{2} \mathrm{CV}=$ coeficiente de variação.

Fonte: Elaboração dos autores.

\section{Conclusão}

A inclusão de até $25 \%$ de feno de amoreira, em substituição parcial ao concentrado à base de farelo de soja e milho em grão moído, não altera o comportamento ingestivo de cordeiros em confinamento.

\section{Agradecimentos}

A Fundação de Amparo à Pesquisa do Estado de São Paulo (FAPESP) por ter financiado este estudo.

\section{Referências}

ALLEN, M. S. Relationship between fermentation acid production in the rumen and the requirement for physically effective fiber. Journal of Dairy Science, Champaign, v. 80, n. 7, p. 1447-1462, 1997.

ALVES, E. M.; PEDREIRA, M. S.; OLIVEIRA, C. A. S.; AGUIAR, L. V.; PEREIRA, M. L. A.; ALMEIDA, P. J. P. Comportamento ingestivo de ovinos alimentados com farelo da vagem de algaroba associado a níveis de ureia. Acta Scientiarum Animal Sciences, Maringá, v. 32, n. 4, p. 439-445, 2010.

BA, N. X.; GIANG, V. D.; NGOAN, L. D. Ensiling of mulberry foliage (Morus alba) and the nutritive value of mulberry foliage silage for goats in central Vietnam. Livestock Research for Rural Development, Cali, v. 17, n. 2, p. 1-9, 2005.

BLAXTER, K. L. The energy metabolism of ruminants. London: Hutchinson \& Company, 1962. 329 p.

BÜRGER, P. J.; PEREIRA, J. C.; QUEIROZ, A. C.; SILVA, J. F. C.; VALADARES FILHO, S. C.; CECON, P. R.; CASALI, A. D. P. Comportamento ingestivo em bezerros holandeses alimentados com dietas contendo diferentes níveis de concentrado. Revista Brasileira de Zootecnia, Viçosa, v. 29, n. 1, p. 236-242, 2000.

CARVALHO, G. G. P.; PIRES, A. J. V.; SILVA, R. R.; VELOSO, C. M.; SILVA, H. G. O. Comportamento ingestivo de ovinos alimentados com dietas compostas de silagem de capim-elefante amonizada ou não e subprodutos agroindustriais. Revista Brasileira de Zootecnia, Viçosa, v. 35, n. 4, p. 1805-1812, 2006.

CARVALHO, G. G. P.; PIRES, A. J. V.; SILVA, R. R.; RIBEIRO, L. S. O.; CHAGAS, D. M. T. Comportamento ingestivo de ovinos Santa Inês alimentados com 
dietas contendo farelo de cacau. Revista Brasileira de Zootecnia, Viçosa, v. 37, n. 4, p. 660-665, 2008.

CARVALHO, G. G.; PIRES, A. J. V.; SILVA, F. F.; VELOSO, C. M.; SILVA, R. R.; SILVA, H. G. O.; BONOMO, P.; MENDONÇA, S. S. Comportamento ingestivo de cabras leiteiras alimentadas com farelo de cacau ou torta de dendê. Pesquisa Agropecuária Brasileira, Brasília, v. 39, n. 9, p. 919-925, 2004.

COSTA, J. L. da; RESENDE, H. Produção de feno de gramíneas. Juiz de Fora: EMBRAPA: CNPGL, 2006. 2 p. (EMBRAPA - CNPGL. Documentos, 19).

CUNHA, M. G. G.; CARVALHO, F. F. R.; VÉRAS, A. S. C.; BATISTA, A. M. V. Desempenho e digestibilidade aparente em ovinos confinados alimentados com dietas contendo níveis crescentes de caroço de algodão integral. Revista Brasileira de Zootecnia, Viçosa, v. 37, n. 6, p. 1103-1111, 2008.

ETHERIDGE, R. D.; PESTI, G. M.; FOSTER, E. H. A comparison of nitrogen values obtained utilizing the Kjeldahl nitrogen and Dumas combustion methodologies (Leco CNS 2000) on samples typical of an animal nutrition analytical laboratory. Animal Feed Science and Technology, Amsterdam, v. 73, n. 1, p. 21-28, 1998.

FERREIRA, D. F. Análises estatísticas por meio do Sisvar para Windows versão 4.0. In: REUNIÃO ANUAL DA REGIÃO BRASILEIRA DA SOCIEDADE INTERNACIONAL DE BIOMETRIA, 45., 2000, São Carlos. Anais... São Carlos: UFSCar, 2000, p. 255-258.

FISCHER, V. Efeito do fotoperíodo, da pressão de pastejo e da dieta sobre o comportamento ingestivo de ruminantes. 1996. Tese (Doutorado em Zootecnia) - Universidade Federal do Rio Grande do Sul, Porto Alegre.

FONSECA, A. S.; FONSECA, T. C. Cultura da amoreira e criação do bicho-da-seda. São Paulo: Nobel, 1986. 246 p.

GILAVERTE, S.; SUSIN, I.; PIRES, A.; FERREIRA, E. M.; MENDES, C. Q.; GENTIL, R. S.; BIEHL, M. V.; RODRIGUES, G. H. Digestibilidade da dieta, parâmetros ruminais e desempenho de ovinos Santa Inês alimentados com polpa cítrica peletizada e resíduo úmido de cervejaria. Revista Brasileira de Zootecnia, Viçosa, v. 40, n. 3, p. 639-647, 2011.

HODGSON, J. Grazing management: science into practice. Inglaterra: Longman Handbooks in Agriculture, 1990. 203 p.

MACEDO, C. A. B.; MIZUBUTI, I. Y.; MOREIRA, F. B.; PEREIRA, S.; RIBEIRO, E. L. A.; ROCHA, M. A.; RAMOS, B. M. O.; MORI, R. M.; PINTO, A. P.; ALVES,
T. C.; CASIMIRO, T. R. Comportamento ingestivo de ovinos recebendo dietas com diferentes níveis de bagaço de laranja em substituição à silagem de sorgo na ração. Revista Brasileira de Zootecnia, Viçosa, v. 36, n. 6, p. 1910-1916, 2007.

MAGALHÃES, A. F.; PIRES, A. J. V.; SILVA, F. F.; CARVAlHO, G. G. P.; CHAGAS, D. M. T.; MAGALHÃES, L. A. Comportamento ingestivo de ovinos alimentados com cana-de-açúcar ensilada com óxido de cálcio ou uréia. Ciência Animal Brasileira, Goiânia, v. 13, n. 1, p. 57-66, 2012.

MENDES, C. Q.; TURINO, V. F.; SUSIN, I.; PIRES, A. V.; MORAIS, J. B.; GENTIL, R. S. Comportamento ingestivo de cordeiros e digestibilidade dos nutrientes de dietas contendo alta proporção de concentrado e diferentes fontes de fibra em detergente neutro. Revista Brasileira de Zootecnia, Viçosa, v. 39, n. 3, p. 594-600, 2010.

NATIONAL RESEARCH COUNCIL - NRC. Nutrients requirements of sheep. Washington: National Academies Press, 2007. 362 p.

PIRES, A. J. V.; CARVALHO, G. G. P.; GARCIA, R.; CARVALHO JÚNIOR, J. N.; RIBEIRO, L. S. O.; CHAGAS, D. M. T. Comportamento ingestivo de ovinos alimentados com silagens de capim-elefante contendo casca de café, farelo de cacau ou farelo de mandioca. Revista Brasileira de Zootecnia, Viçosa, v. 38, n. 8, p. 1620-1626, 2009.

POLLI, V. A. RESTLE, J.; SENNA, D. B.; ALMEIDA, $\mathrm{S}$. R. S. Aspectos relativos à ruminação de bovinos e bubalinos em regime de confinamento. Revista Brasileira de Zootecnia, Viçosa, v. 25, n. 5, p. 987-993, 1996.

PRASAD, P. E.; REDDY, M. R. Nutritive value of mullberry (Morus alba) leaves in goats and sheep. Indian Journal of Animal Nutrition, New Delhi, v. 8, n. 4, p. 295-296, 1991.

SANCHEZ, M. D. Mulberry: an exceptional forage available almost worldwide. In: SANCHEZ, M. D. Mulberry for animal production. Roma: Food and Agriculture Organization (FAO) of United Nations, 2002. p. 271-289.

SILVA, D. C.; ALVES, A. A.; OlIVEIRA, M. E.; MOREIRA FILHO, M. A.; RODRIGUES, M. M.; VALE, G. E. S.; NASCIMENTO, H. T. S. Consumo e digestibilidade de dietas contendo farelo de mamona destoxificado para ovinos em terminação. Revista Brasileira de Saúde e Produção Animal, Salvador, v. 12, n. 1, p. 96-106, 2011.

SILVA, D. J.; QUEIROZ, A. C. Análise de alimentos: métodos químicos e biológicos. 3. ed. Viçosa: UFV, 2002. $235 \mathrm{p}$. 
SNIFFEN, C. J.; CONNOR, J. D.; VAN SOEST, P. J. A net carbohydrate and protein system for evalution cattle diets. II Carboydrate and protein availability. Journal of Animal Science, Champaign, v. 70, n. 11, p. 3562-3577, 1992.
TAKAHASHI, R. Sericicultura: Amoreira (Morus alba L.) Bicho da Seda (Bombyx mori L.). Jaboticabal: FCAV/ UNESP, 1988. $135 \mathrm{p}$.

VAN SOEST, P. J. Nutritional ecology of the ruminant. New York: Cornell University Press, 1994. 476 p. 